\title{
Méiose et différenciation germinale en culture
}

Malgré l'importance de la différenciation germinale - responsable de la préservation et de la diversification de notre patrimoine génétique - relativement peu est encore connu des mécanismes moléculaires et des régulations impliqués dans ses deux grandes étapes, la méiose et la gamétogenèse. Un ensemble complexe de régulations hormonales est certes bien analysé, mais elles aboutissent, en fait, à une sorte de "boîte noire" au niveau des cellules germinales. La difficulté vient en grande partie de ce que l'on ne sait pas maintenir ces cellules en culture, ce qui interdit les approches expérimentales qui ont fait les succès de la génétique moléculaire. Or, il est clair que, sans la puissance de l'outil génétique, la complexité du système laisse peu d'espoir à l'analyse. En se limitant au testicule (l'ovaire pose les mêmes problèmes avec une difficulté d'accès encore plus importante), cette complexité est d'emblée apparente au vu de l'architecture élaborée du tube séminifère, et de son fonctionnement cyclique rigoureusement contrôlé [1]. Au niveau moléculaire, on sait qu'un très grand nombre de gènes, soit sont exprimés uniquement dans le testicule, soit y sont exprimés sous une forme qui diffère de celle de la cellule somatique par un changement d'épissage ou de promoteur [2, 3]. Cependant, de récents résultats devraient permettre de progresser enfin dans la compréhension de ce complexe système de différenciation.

En effet, les résultats récemment publiés par Rassoulzadegan, Cuzin et al. (Inserm U.273, Université de Nice. Sophia. Antipolis) [4] devraient permettre de développer in vitro une approche au niveau moléculaire. Des lignées de souris transgéniques possédant le gène codant pour l'antigène $T$ du virus du polyome avaient été construites dans ce laboratoire. L'expression de cette protéine permet d'immortaliser des clones cellulaires en culture, sans toutefois y induire un état tumoral avancé, en principe peu compatible avec un fonctionnement physiologique normal. Dans une série de lignées, le transgène est exprimé dans l'épithélium séminifère. Des lignées permanentes ont pu être établies à partir du testicule de ces animaux, et certaines montrent, en culture, des propriétés caractéristiques de la cellule de Sertoli : morphologie et ultra-structure, expression des gènes Steel $\left(\mathrm{m} / \mathrm{s} n^{\circ} 10\right.$, vol. $6, p .1016$ ) et $\mathrm{WT} 1$ (Wilms tumor 1). Sachant que, dans le testicule, la cellule germinale ne fonctionne que dans le micro-environnement créé par ces cellules somatiques, on admettait qu'établir une culture germinale présupposait l'établissement d'une culture sertolienne.

Cependant, les efforts de nombreuses équipes s'étaient révélés décevants, ces cultures dégénérant rapidement. Or, de même qu'in vivo la cellule de Sertoli qui exprime le transgène grand $T$ reste fonctionnelle, les cellules établies in vitro conservent un fonctionnement relativement normal - assez en tout cas pour que des cellules germinales puissent, à leur contact, passer les étapes successives de la méiose. Dans certaines conditions, la différenciation se poursuit jusqu'au spermatozoïde [4].

Les perspectives ouvertes sont mul- tiples, en particulier si cette nouvelle technique peut être couplée avec les méthodes performantes de la génétique moléculaire. Au niveau fondamental, ce peut être l'identification des gènes et protéines impliqués dans les mécanismes complexes de la méiose et de la recombinaison homologue, et leur régulation. A l'heure des interrogations écologiques sur les pollutions de la biosphère et des réflexions bioéthiques sur le maintien de l'intégrité de notre patrimoine génétique, ce peut être un outil pour l'analyse des eff ets d'agressions physiques, chimiques, virales sur la lignée germinale, et le développement de moyens de protection. Au plan médical, l'analyse des causes des nombreuses stérilités mâles encore inexpliquées pourra être envisagée, débouchant peut-être sur des perspectives thérapeutiques $\left(\mathrm{m} / \mathrm{s} n^{\circ} 3\right.$, vol. $\left.10, p .334\right)$.

F.C.

1. Russell LI), Ettlin RA, Sinha Hikim AP, Clegg EI). Histological and histopathological evaluation of the testis. Clearwater, F1: Cache River Press, 1990.

2. Wolgemuth DJ, Watrin F. List of cloned mouse genes with unique expression patterns during spermatogenesis. Mammalian Genome $1991 ; 1$ : 283-8.

3. Barouki R. Expression des gènes au cours de la spermatogenèse. médecine/sciences 1992 ; 8: $523-40$.

4. Rassoulzadegan M, Paquis-Flucklinger V, Bertino B, Sage J, Jasin M, Miyagawa K, van Heyningen V, Besmer P, Cuzin F. Transmeiotic differentiation of male germ cells in culture. Cell 1993; 75 : 997-1006. 